\title{
Comparison of Different Muscle-Relaxant Anesthetics on Growth, Migration and Invasion of Gastric Cancer Cells
}

\author{
AIHUA JIANG $^{1 *}$, HUISHAN ZHAO ${ }^{1 *}$, XIAOFEI LIU ${ }^{1}$, MINGWEI YU ${ }^{1}$, JIAN CHEN $^{1}$ and WEN G. JIANG ${ }^{2}$ \\ ${ }^{1}$ Affiliated Yantai Yuhuangding Hospital of Qingdao University, Yantai, P.R. China; \\ ${ }^{2}$ Cardiff-China Medical Research Collaborative, Cardiff University School of Medicine, Cardiff, U.K.
}

\begin{abstract}
Background/Aim: Muscle relaxants, also known as neuromuscular blocking agents, can block nerve impulses to the muscles and are always used in surgery for general anesthesia. However, the effect of muscle-relaxant anesthetics on cell activity in gastric cancer is currently unknown. The present study aimed to examine and compare the role of three different muscle-relaxant anesthetics in gastric cancer cells. Materials and Methods: Gastric cancer cells (SGC7901 and BGC 823) were treated with a different dose of muscle-relaxant anesthetics, Rocuronium bromide $(R b)$, Vecuronium bromide $(\mathrm{Vb})$ and Cisatracurium Besilate $(\mathrm{CB})$. Using in vitro models, the effects on gastric cancer cell invasion, growth and migration of various anesthetics were subsequently investigated. Results: We found that $R b$ increased the growth, invasion and migration of gastric cancer cells SGC7901 and BGC823. However, Vb and CB, as relatively mitigative anesthetics, did not significantly affect gastric cancer cell malignant phenotype at their regular blood concentration. Conclusion: Our results are important in selecting the type and dose of anesthetic used for surgery of gastric cancer patients. An understanding of the effect of muscle-relaxant anesthetics and their impact on tumor metastasis is critical, since it provides insight into the appropriate anesthetic strategy that could improve long-term survival in some patients with gastric cancer. Gastric cancer (GC) is a highly lethal malignancy worldwide, particular in developing countries, which makes it a key public health problem $(1,2)$. The conventional
\end{abstract}

*These Authors contributed equally to this study.

Correspondence to: Prof. Wen G. Jiang, Cardiff-China Medical Research Collaborative, Cardiff University School of Medicine, Heath Park, Cardiff CF14 4XN, U.K. Tel: +44 2920687065, e-mail: jiangw@cardiff.ac.uk

Key Words: Anesthetics, migration, breast cancer, invasion, $\mathrm{Rb}, \mathrm{Vb}$, $\mathrm{CB}$. treatment for GC includes radiotherapy, routine surgery, hormone therapy and biotherapy. However, when tumors progress there is a risk that not all of the tumor tissue is surgically removed $(3,4)$. Anesthetics are administered to facilitate surgery. Some factors including anesthetic techniques and anesthetic drugs may affect the activity of residual tumor cells after surgery and facilitate cancer recurrence and/or metastasis (5).

Tumor metastasis is the spread of cells from the primary tumor to new locations in the body, through the circulatory and lymphatic system, and is considered the main cause of cancer-related death. Metastatic tumor cells show different genomic and epigenetic profiles generally associated with aggressive traits. The analgesia technique and the anesthetic agents used during surgical tumor resection have been determined as pathogenic factors for cancer recurrence/ metastasis. Thus, anesthesiologists take enormous responsibility in decreasing metastasis/recurrence rate of cancer, both during the perioperative period and postoperative analgesia period. There is evidence to suggest that anesthetics may potentially have a role in tumor metastasis (6-8). A better understanding of the mechanisms of metastatic disease and identification of regulators of metastasis, including how metastatic tumor cells invade and grow in the local microenvironment, would enable the treatment and development of metastatic prevention strategies.

The effect of anesthetics on cancer metastasis has been unveiled gradually. Some anesthetics were considered an important factor in cancer metastasis. Recently, a review summarized the effect of anesthesia on tumor metastasis, including anesthetic and analgesic techniques (5), suggesting that anesthetics are a non-negligible issue in clinical practice. Propofol was investigated in several kinds of cancers and in gastric cancer has been shown to have an inhibitory role in the growth and survival of gastric cancer cells through up-regulating ING3 (9). In another study propofol inhibited proliferation and apoptosis by regulating microRNA-451 and MMP-2 expression (10). Propofol has also been shown to have an effect on the metastasis of other cancer cells such as ovarian (11), lung (12) and 
A<smiles>C=CCN1CCCC1C1CC2C3CCC4CC(O)C(N5CCOCC5)CC4C3CCC2C1OC</smiles>

B

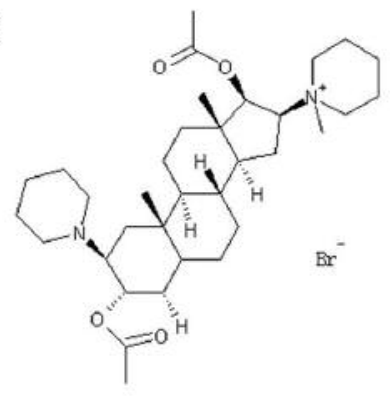

C

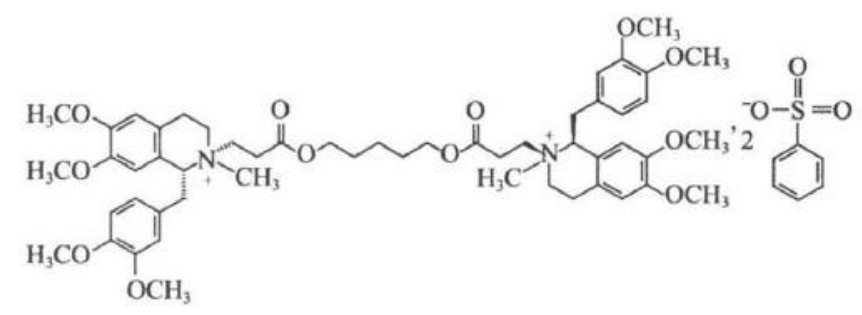

Figure 1. Chemical structures of $R b(A), V b(B)$ and $C B(C)$.

prostate cancer (13). Increasing numbers of reports on procaine have suggested that low dosage of procaine suppressed the proliferation of lung cancer cells, however this did not appear with higher doses (14). Procaine has also been seen to affect osteosarcoma cells, by inhibiting their migration and growth possibly through inducing cell apoptosis (15). Muscle relaxants, including Rocuronium bromide $(\mathrm{Rb})$, Vecuronium bromide $(\mathrm{Vb})$ and Cisatracurium Besilate (CB), act as effective anesthetics by blocking the nerve impulses to the muscles, and thus are generally used in surgery for general anesthesia. Currently there is little research on the effect of muscle relaxants on tumor metastasis. Last year, our team concentrated on muscle relaxants' impact on breast cancer metastasis. Interestingly, we found that $\mathrm{Rb}$ promoted breast cancer cell growth, migration and invasion, but $\mathrm{Vb}$ did not (16). In this study, we investigated how muscle relaxants affect the activity of gastric cancer cells.

\section{Materials and Methods}

Cell culture. Gastric cancer cells SGC7901 and BGC 823 were obtained from China Centre for Type Culture Collection (Shanghai, China). These two wild-type cancer cells were routinely cultured in RPMI-1640 (Life Technologies Corporation, USA) supplemented with $10 \%$ foetal calf serum (FCS; PAA Laboratories, Somerset, UK), penicillin and streptomycin (Sigma-Aldrich Inc, Poole, Dorset, $\mathrm{UK})$ ), in an incubator at $37.0^{\circ} \mathrm{C}, 5 \% \mathrm{CO}_{2}$ and $95 \%$ humidity.

Muscle relaxants for anesthesia. Three kinds of muscle relaxant anesthetics, $\mathrm{Rb}, \mathrm{Vb}$ and $\mathrm{CB}$, were purchased from Sigma (SigmaAldrich, Dorset, UK). They were all dissolved in PBS and stored at $4{ }^{\circ} \mathrm{C}$ until use. The doses used during experiments were based on the clinical dosages used by the anesthesiologist for which $\mathrm{Rb}, \mathrm{Vb}$ and $\mathrm{CB}$ were $0.6 \mathrm{mg} / \mathrm{kg}, 0.1 \mathrm{mg} / \mathrm{kg}$ and $0.2 \mathrm{mg} / \mathrm{kg}$ respectively. Dilution ranges were as follows: $\mathrm{Rb}-8 / 80 \mu \mathrm{g} / \mathrm{ml}, \mathrm{Vb}-.5 / 15 \mu \mathrm{g} / \mathrm{ml}$ and $\mathrm{CB}$ $-2.5 / 25 \mu \mathrm{g} / \mathrm{ml}$.

In vitro cell growth assays. For each cell line 3,000 cells/200 $\mu 1 /$ well were added to a 96-well plate (BEAVER, Suzhou, China) and incubated for 1 to 5 days (1, 3, 4 and 5 days respectively). After incubation, culture medium was removed and replaced with $100 \mu \mathrm{l}$ of 10\% CCK-8 (Cell Counting Kit-8, Dojindo, Japan). Absorbance of the solution was determined using a spectrophotometer (Thermo Fisher Scientific) at a wavelength of $450 \mathrm{~nm}$.

In vitro cell scratch assay. Cells were seeded into 12 -well plates and cultured overnight to allow the formation of a confluent monolayer. Subsequently an artificial wound in the monolayer was created by using a $200-\mu$ pipette tip to scratch a wound. The cell monolayer was washed twice with PBS to remove floating cells. Migration of cells, monitored by the closing of the artificial wound space was recorded every $6 \mathrm{~h}$ using an inverted microscope over a period up to $24 \mathrm{~h}$. The sizes of the wounds were subsequently analyzed using Image $\mathrm{J}$ software.

In vitro cell adhesion assay. Six-well plates were pre-coated with 5 $\mu \mathrm{g} / 100 \mu \mathrm{l} /$ well Matrigel (BD Matrigel ${ }^{\mathrm{TM}}$ Basement Membrane Matrix, Corning, Tewksbury MA, USA) diluted in serum free media and dried to form an artificial basement membrane. Following rehydration with serum-free media for $40 \mathrm{~min}, 20,000$ cells/200 $\mu \mathrm{l}$ were added into each well. After 4 min incubation culture medium was removed and the wells were washed with PBS to remove any non-adherent cells. Adherent cells were fixed with $4 \%$ formalin for $30 \mathrm{~min}$. After washing each well twice with PBS, adherent cells were stained with $0.5 \%$ crystal violet. Crystal violet staining was dissolved with $10 \%$ acetic acid and measured using a spectrophotometer (Thermo Fisher Scientific) at a wavelength of $540 \mathrm{~nm}$. 
SGC7901

A

\section{Rocuronium bromide}

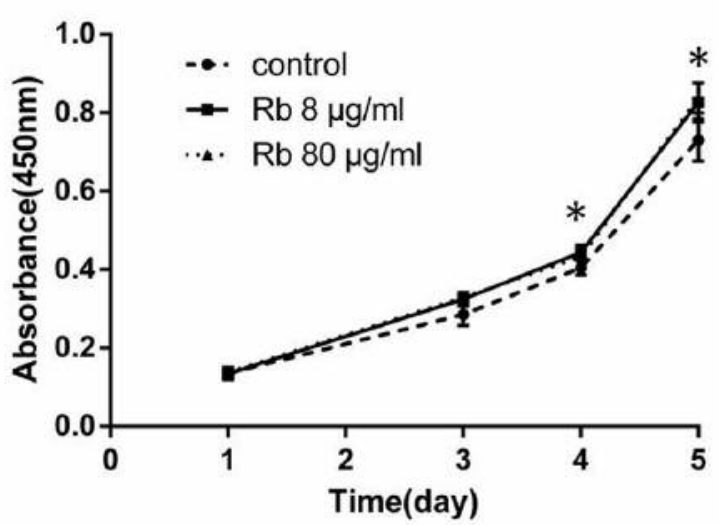

C

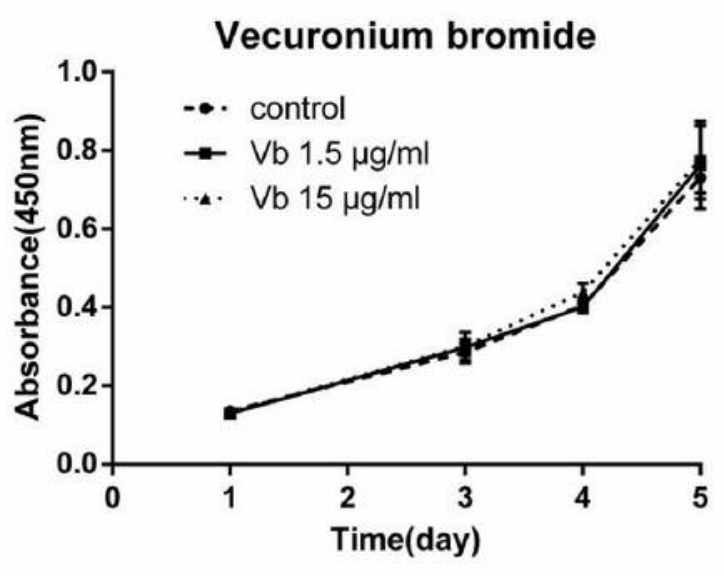

$\mathbf{E}$

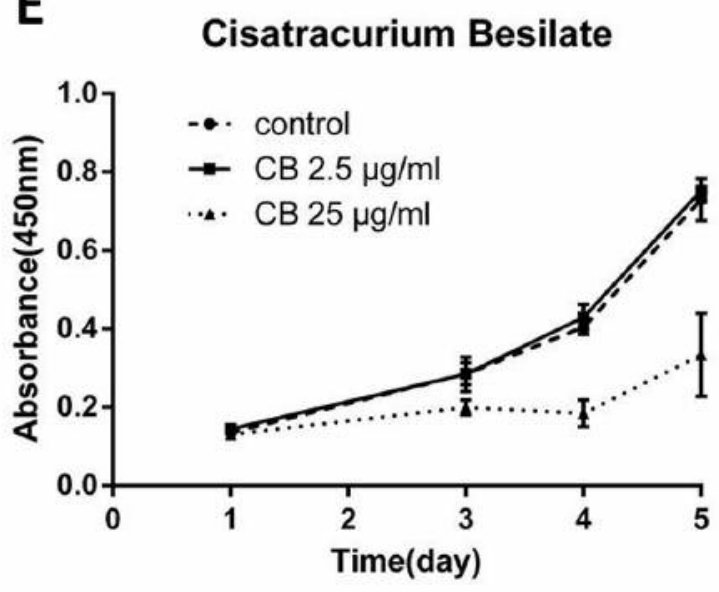

BGC823

B

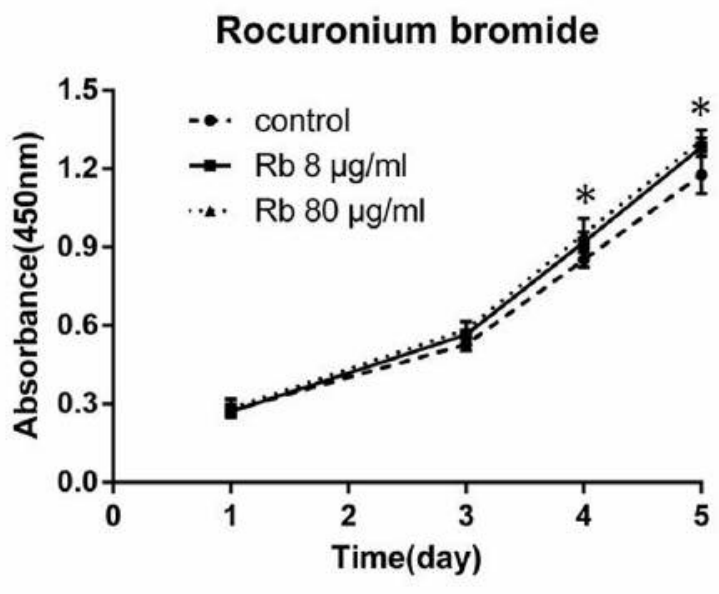

D

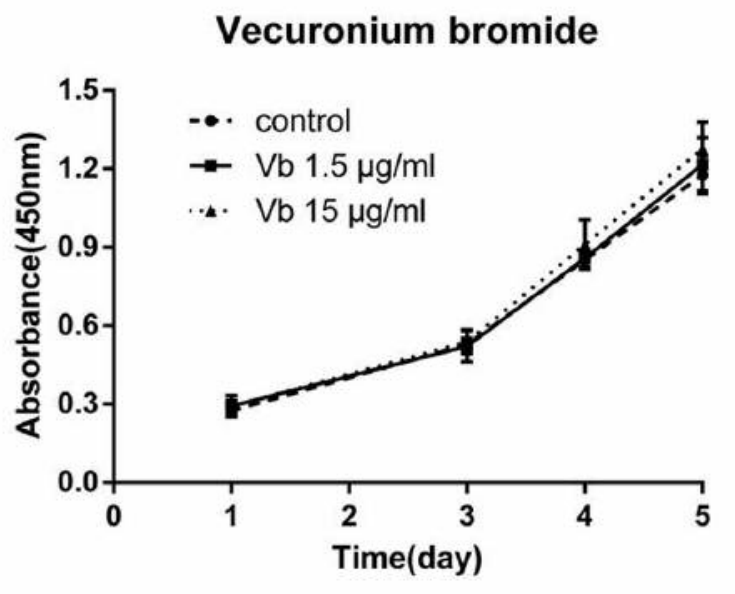

$\mathbf{F}$

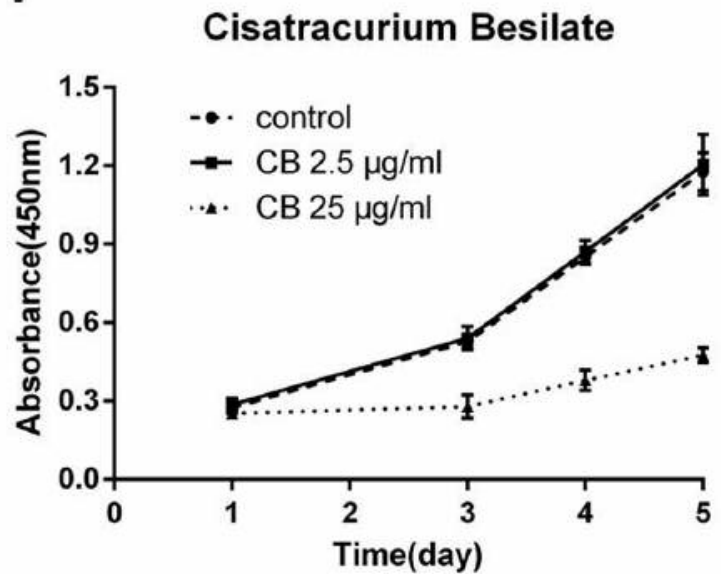

Figure 2. Effects of Rb, $\mathrm{Vb}$ and $C B$ on growth of gastric cancer cells in vitro. Rb increased the proliferation of $S G C 7901$ (A) and BGC823(B) in vitro. Vb had no significant effect on the growth of SGC7901 (C) and BGC823 (D) cells. CB hardly stimulated the growth of SGC7901 (E) and $B G C 823(F)$ in vitro, but overdose could result in partial cell death $(* p<0.05, * * p<0.01$ vs. control with no treatment). 


\section{SGC7901}

A
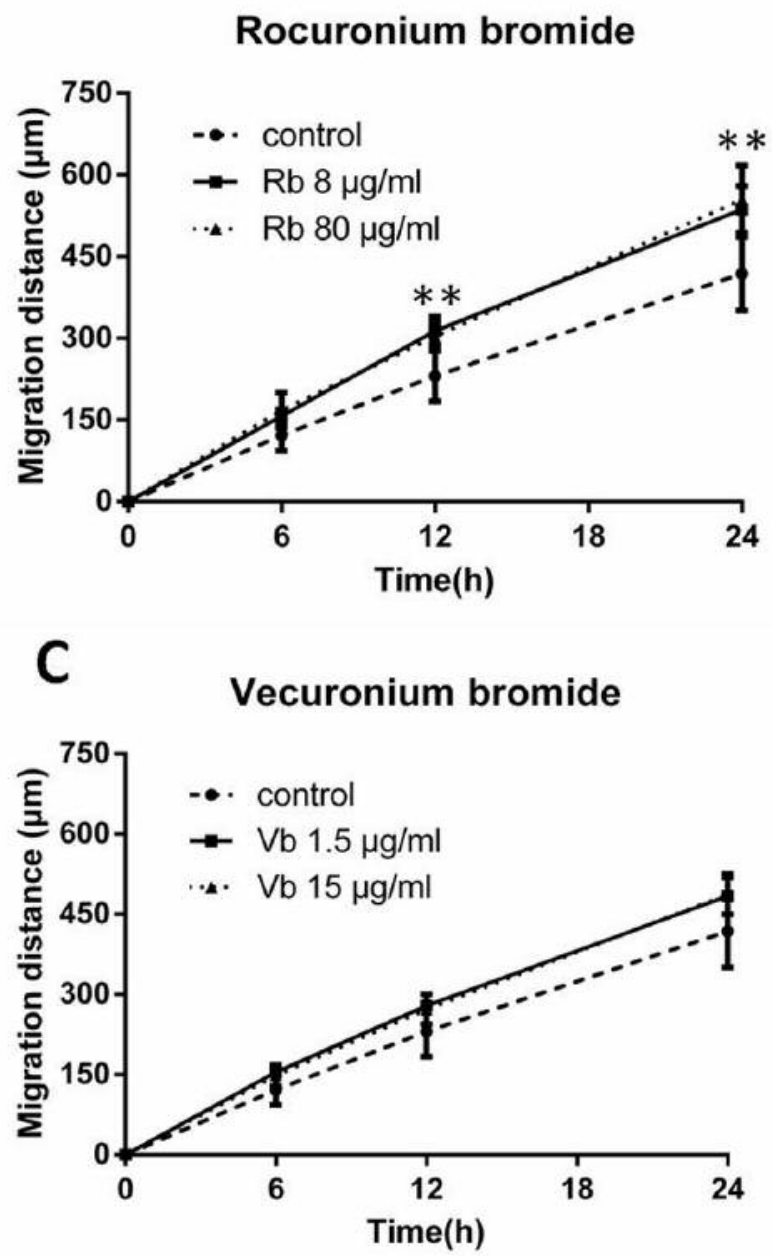

E Cisatracurium Besilate

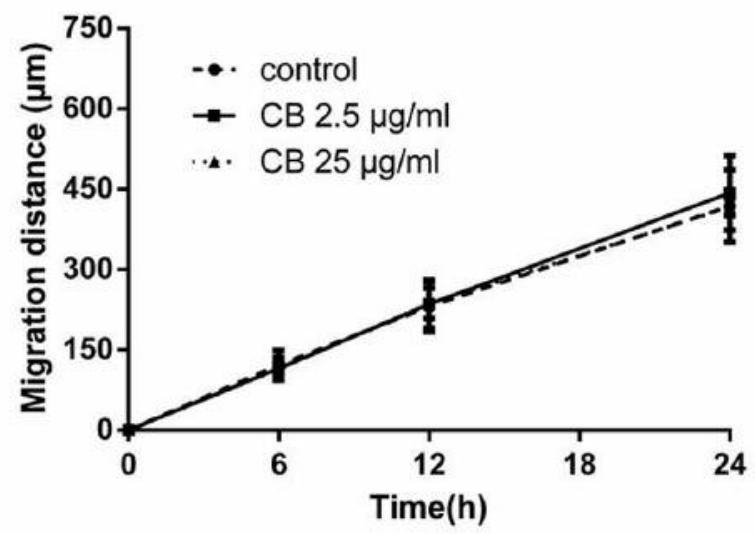

B

\section{BGC823}

\section{Rocuronium bromide}
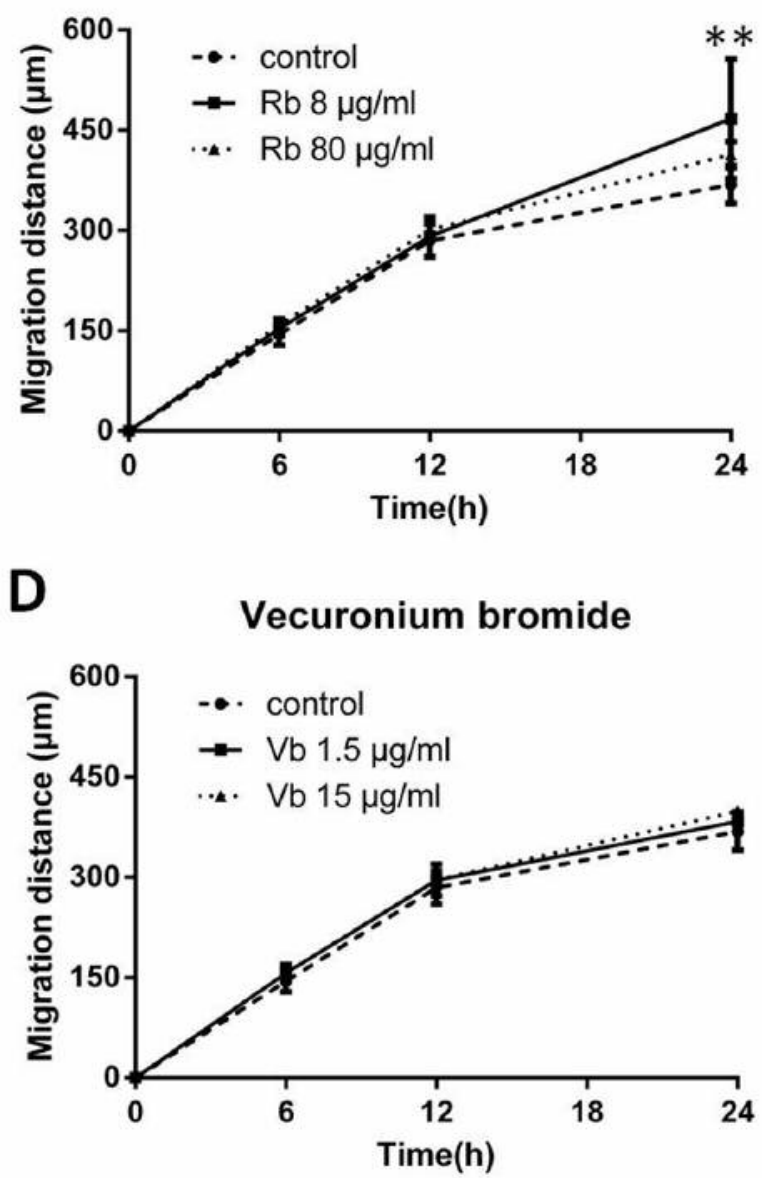

$\mathbf{F}$

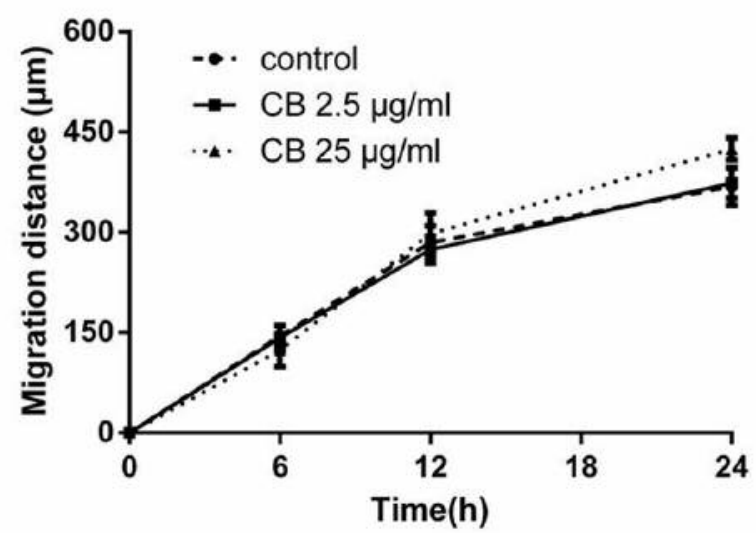

Figure 3. The effect of $R b, V b$ and $C B$ on migration of gastric cancer cells in vitro. A: Rb promoted the migration of SGC7901 (A) and BGC823 $(B) . V b$ had no effect on the migration of $S G C 7901(C)$ and $B G C 823(D)$ at the regular blood concentration in vitro, but facilitated the migration at tenfold blood concentration. $C B$ hardly affected SGC7901 (E) and BGC823 (F) migration in vitro. 
A

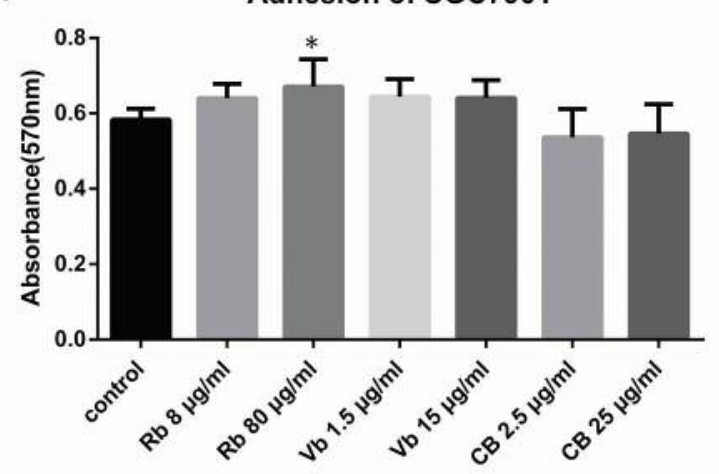

C

SGC7901

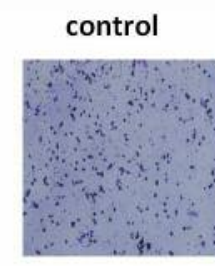

$\mathrm{Rb} 8 \mu \mathrm{g} / \mathrm{ml}$

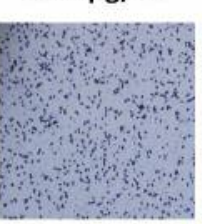

$\mathrm{Rb} 80 \mu \mathrm{g} / \mathrm{ml}$

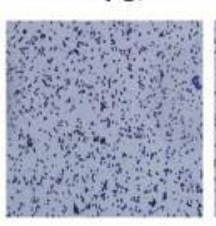

BGC823
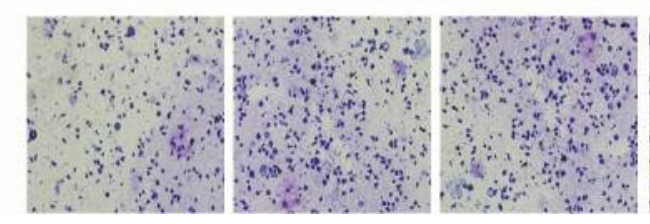

B

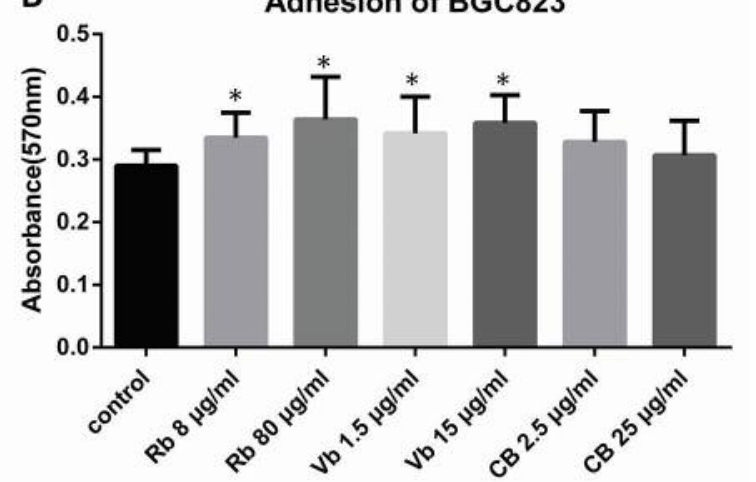

$\mathrm{Vb} 1.5 \mu \mathrm{g} / \mathrm{ml}$

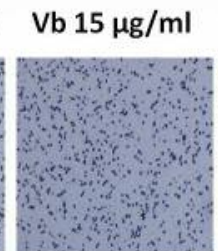

CB $2.5 \mu \mathrm{g} / \mathrm{ml}$

CB $25 \mu \mathrm{g} / \mathrm{ml}$
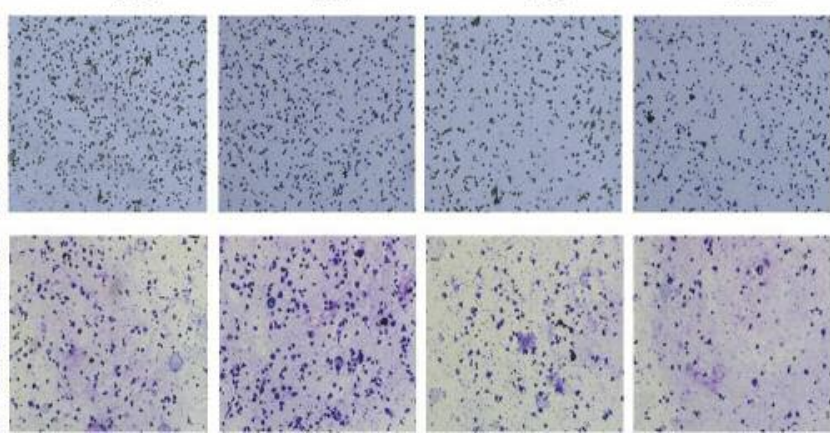

Figure 4. The effect of $R b, V b$ and $C B$ on adhesion of gastric cancer cells. Rb increased the adhesion of SGC7901 (A) at tenfold blood concentration in vitro. $R b$ and $V b$ affected the adhesion of BGC823 $(B)$ and reached statistical significance. Representative data of adhesion assay for SGC7901 and BGC823 cells treated with different concentration of muscle-relaxant anesthetics for $40 \mathrm{~min}(C)$.

In vitro cell invasion assay. Transwell chambers $(8-\mu \mathrm{m}$ pore size) polycarbonate filter inserts $(6.5 \mathrm{~mm}$ diameter) (Becton Dickinson and Company, Oxford, UK), were coated with $50 \mu \mathrm{g}$ Matrigel/100 $\mu \mathrm{l} /$ insert (BD Matrigel ${ }^{\mathrm{TM}}$ Basement Membrane Matrix) and air-dried. Following rehydration, 20,000 cells/200 $\mu \mathrm{l}$ were seeded into inserts with $5 \%$ foetal calf serum and $1 \mathrm{ml}$ with $10 \%$ foetal calf serum medium in bottom well. After $48 \mathrm{~h}$, the cells that invaded through the Matrigel were fixed, stained, and quantified as described previously (17).

Statistical analysis. Statistical analysis was performed using Minitab statistical software package (version 14) and Graphpad. Differences were considered to be statistically significant at $p<0.05$.

\section{Results}

Chemical structures of muscle relaxant anesthetics Rocuronium bromide (Rb), Vecuronium bromide (Vb) and Cisatracurium Besilate $(C B)$. Clinically, $\mathrm{Rb}\left(\mathrm{C}_{32} \mathrm{H}_{53} \mathrm{BrN}_{2} \mathrm{O}_{4}\right)$, $\mathrm{Vb}\left(\mathrm{C}_{34} \mathrm{H}_{57} \mathrm{BrN}_{2} \mathrm{O}_{4}\right)$ and $\mathrm{CB}\left(\mathrm{C}_{65} \mathrm{H}_{82} \mathrm{~N}_{2} \mathrm{O}_{18} \mathrm{~S}_{2}\right)$ are widely used to induce and maintain anesthesia in patients undergoing gastric cancer resection surgery. The chemical structures of $\mathrm{Rb}$ (Figure 1A), Vb (Figure 1B) and CB (Figure 1C) are shown in Figure 1.
$R b$ promoted gastric cancer cell growth. When compared to the untreated control group $\mathrm{Rb}$ resulted in a significant increase in gastric cancer cell growth, in SGC7901 $(p<0.05)$ (Figure $2 \mathrm{~A}$ ) and BGC823 cells $p<0.05$ ) (Figure 2B), when treated with regular blood concentration and a tenfold blood concentration, though a concentration dependent effect was not observed. When SGC7901(Figure 2C) and BGC823 cells (Figure 2D) were cultured with $\mathrm{Vb}(1.5 \mu \mathrm{g} / \mathrm{ml}$ and $15 \mu \mathrm{g} / \mathrm{ml})$, high concentration $\mathrm{Vb}$ marginally promoted cell proliferation, whilst low concentration had no effect. $\mathrm{CB}$ did not result in a significant change on the growth of gastric cancer cells, but the tenfold concentration did (Figure 2E and 2F).

Differing effects of $R b, V b$ and $C B$ on the migration of gastric cancer cells in vitro. The scratch wounding assay showed that $\mathrm{Rb}$ facilitated the movement of SGC7901 (Figure 3A) and BGC823 (Figure 3B) cells compared to the untreated control both at $8 \mu \mathrm{g} / \mathrm{ml}$ and $80 \mu \mathrm{g} / \mathrm{ml}$ and reached statistical significance $(p<0.05)$. This increase in SGC7901 gastric cancer cell migration was also oberved when treated with $\mathrm{Vb}$ (Figure 3C), however this did not reach statistical 
A

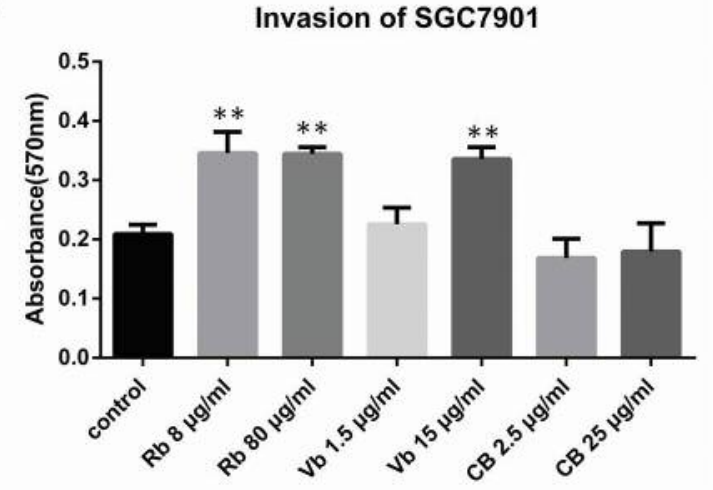

B

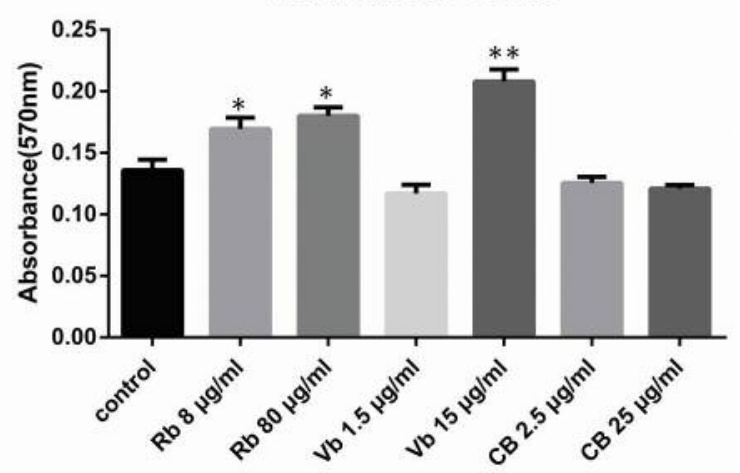

C
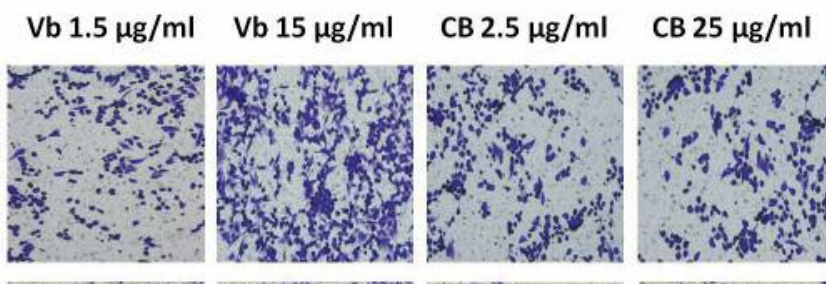

SGC7901
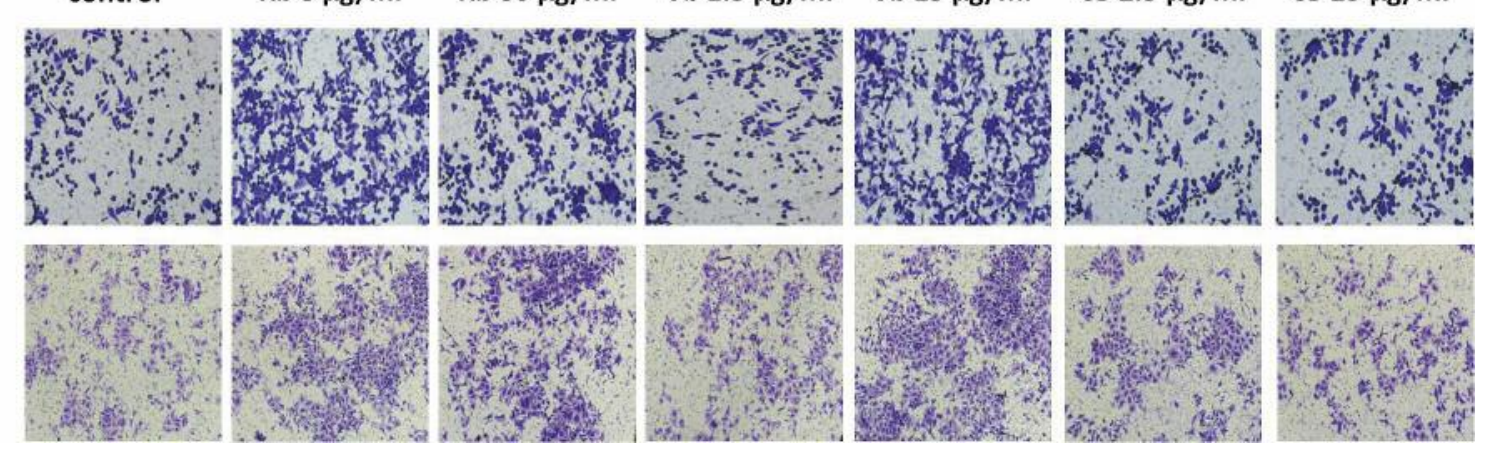

Figure 5. The effect of $R b, V b$ and $C B$ on invasion of gastric cancer cells in vitro. Rb and tenfold blood concentration Vb induced the invasion of SGC7901 (A) and BGC823 (B) in vitro. Representative data of transwell assay for SGC7901 and BGC823 cells treated with different concentrations of muscle-relaxant anesthetics for $48 \mathrm{~h}(\mathrm{C})$.

significance. This trend was not observed in BGC 823 gastric cancer cells (Figure 3D). High CB concentration could also increase cell migration.

$R b$ and $V b$ inceased the adhesion of gastric cancer cells. Both in SGC7901 (Figure 4A) and BGC823 cell lines (Figure 4B), $\mathrm{Rb}$ and $\mathrm{Vb}$ promoted cell adhesion in a concentrationdependent manner. CB had no significant effect on the adhesive properties of gastric cancer cells. Representative data from the adhesion assay in SGC7901 and BGC823 cells treated with different concentration muscle-relaxant anesthetics for $40 \mathrm{~min}$ are shown in Figure 4C.

Comparison between $R b, V b$ and $C B$ with the control group (no treatment) on the invasion in vitro. In order to explore the effect of $\mathrm{Rb}, \mathrm{Vb}$ and $\mathrm{CB}$ on gastric cancer cell invasion, we used an established in vitro technique. $\mathrm{Rb}$ significantly increased the invasive potential of SGC7901 and BGC823 cells but $\mathrm{CB}$ did not (Figure 5A and B). Invasion did not change upon treatment with $\mathrm{Vb}$ at a regular blood concentration, however a tenfold blood concentration facilitated cell invasion.
Figure 5C displays the representative figures and data of the invasion assays for SGC7901 and BGC823 cells treated with different concentrations of muscle-relaxant anesthetics for $48 \mathrm{~h}$.

\section{Discussion}

Anesthetics are unavoidable for patients with gastric cancer who receive surgical treatment. Gastric cancer patients often show high sensitivity to some anesthetics; however, the mechanism by which these anaethetics affect tumor metastasis remains poorly understood. Muscle-relaxant anesthetics are widely used in the induction and maintenance of anesthesia as adjunctive drugs for patients undergoing gastric cancer surgery. In the present study, we focused on the effect of $\mathrm{Rb}, \mathrm{Vb}$ and $\mathrm{CB}$ on gastric cancer cell function in vitro. We attempted to discover the most appropriate anesthetics that exert the least pro-metastatic effects on gastric cancer cells.

Recently, accumulating clinical evidence suggested that both anesthetics and the technology of anesthesia influenced the efficacy of patients undergoing surgery for various 
cancers (18-20). The impact of multiple anesthetics on tumor metastasis was gradually brought to light. For example, propofol inhibited the migratory ability of cervical carcinoma cells by altering cellular morphology (21). A report regarding lidocaine indicated that lidocaine supressed the migration and invasion of TRPV6-expressing cancer cells through downregulating TRPV6 (22). Anaesthetic techniques act as vital parts of surgery treatment, as it might affect the serum environment in a way which subsequently influences cancer cell biology, and therefore tumor metastasis (23).

Research into $\mathrm{Rb}$ and $\mathrm{Vb}$ mainly refers to its effects on neurones (24-26), but wider effects have not been investigated in vitro. Thus, it is important to study the effect of muscle-relaxant anesthetics, especially $\mathrm{Rb}, \mathrm{Vb}$ or $\mathrm{CB}$, on tumor metastasis both in vitro and in vivo. Interestingly, their impact on the partial malignant phenotype of breast cancer cells has been previously reported (16). In continuation to our previous studies, we explored the effect of $\mathrm{Rb}, \mathrm{Vb}$ and $\mathrm{CB}$ on gastric cancer cell activity. We found that $\mathrm{Rb}$ increased the gastric cancer cell malignant phenotype including growth, invasion and migration. Certainly, $\mathrm{Rb}$ has the advantage of operating quickly. In summary, $\mathrm{Rb}$ is not recommended to be used in patients with cancer, considering survival prognosis and recurrence. $\mathrm{Vb}$ and $\mathrm{CB}$ rarely affected cell growth and activity at a regular blood concentration, yet an overdose of $\mathrm{Vb}$ induced migration and invasion of SGC7901 and BGC823 cells. Also, since muscle-relaxant anesthetics were able to kill normal breast MCF-10A cells in our previous study, we suspected that an overdose of $\mathrm{CB}$ could damage both normal and tumor cells. Hence, the growth rate of gastric cancer cells decreased when treated with a tenfold blood concentration of $\mathrm{CB}$.

In conclusion, these results provided important information that may be useful regarding the clinical application of these anesthetics. We characterized $\mathrm{Rb}$ as a stimulant of gastric cancer cell growth, migration and invasion in vitro. $\mathrm{Vb}$ and CB hardly affected the malignant phenotype at their regular blood concentration. Our results provided an instructive choice and dose in selecting muscle-relaxant anesthetic during gastric cancer surgery . Thus, we suggest that it is better to use $\mathrm{Vb}$ and $\mathrm{CB}$ in gastric cancer surgery. $\mathrm{Rb}$ should be carefully used in patients with gastric cancer due to its role for prompting gastric cancer progression.

However, anesthetists always use more than one anesthetic to reach anesthesia. Different anesthetics may interact with each other and affect the tumor progression. Therefore, through further study, we would investigate the effect of anesthetics on cancer metastasis when treated with several anesthetics at the same time. Accumulated evidence over these years has provided an insight into the importance of the most proper anesthetics for different diseases in attenuating tumor metastasis, thereby having a favorable long-term outcome.

\section{Acknowledgements}

The Authors would like to thank Cancer Research Wales for supporting this study. They also thank Dr Jane Lane and Dr Sioned Owen for proof reading the manuscript.

\section{References}

1 Siegel R, Ma J, Zou Z and Jemal A: Cancer statistics, 2014. CA Cancer J Clin 64: 9-29, 2014.

2 Ferlay J, Soerjomataram I, Dikshit R, Eser S, Mathers C, Rebelo M, Parkin DM, Forman D and Bray F: Cancer incidence and mortality worldwide: sources, methods and major patterns in GLOBOCAN 2012. Int J Cancer 136: E359-386, 2015.

3 Porter PL: Global trends in breast cancer incidence and mortality. Salud publica de Mexico 51(Suppl 2): s141-146, 2009.

4 Gluck S and Mamounas T: Improving outcomes in early-stage breast cancer. Oncology 24: 1-15, 2010.

5 Vahabi S and Eatemadi A: Effects of anesthetic and analgesic techniques on cancer metastasis. Biomed Pharmacother 87: 1-7, 2017.

6 Tazawa K, Koutsogiannaki S, Chamberlain M and Yuki K: The effect of different anesthetics on tumor cytotoxicity by natural killer cells. Toxicol Lett 266: 23-31, 2017.

7 Deng F, Ouyang M, Wang X, Yao X, Chen Y, Tao T, Sun X, Xu L, Tang $J$ and Zhao L: Differential role of intravenous anesthetics in colorectal cancer progression: implications for clinical application. Oncotarget 7: 77087-77095, 2016.

8 Le-Wendling L, Nin O and Capdevila X: Cancer recurrence and regional anesthesia: the theories, the data, and the future in outcomes. Pain Med 17: 756-775, 2016.

9 Yang C, Gao J, Yan N, Wu B, Ren Y, Li H and Liang J: Propofol inhibits the growth and survival of gastric cancer cells in vitro through the upregulation of ING3. Oncol Rep 37: 587-593, 2017.

10 Peng $\mathrm{Z}$ and Zhang Y: Propofol inhibits proliferation and accelerates apoptosis of human gastric cancer cells by regulation of microRNA-451 and MMP-2 expression. Genetics Mol Res 15, 2016. doi: 10.4238/gmr.15027078.

$11 \mathrm{Su} \mathrm{Z}$, Hou XK and Wen QP: Propofol induces apoptosis of epithelial ovarian cancer cells by upregulation of microRNA let7i expression. Eur J Gynaecol Oncol 35: 688-691, 2014.

12 Cui WY, Liu Y, Zhu YQ, Song T and Wang QS: Propofol induces endoplasmic reticulum (ER) stress and apoptosis in lung cancer cell H460. Tumor Biol 35: 5213-5217, 2014.

13 Huang H, Benzonana LL, Zhao H, Watts HR, Perry NJ, Bevan $\mathrm{C}$, Brown $\mathrm{R}$ and Ma D: Prostate cancer cell malignancy via modulation of HIF-1alpha pathway with isoflurane and propofol alone and in combination. Brit J Cancer 111: 1338-1349, 2014.

14 Ma XW, Li Y, Han XC and Xin QZ: The effect of low dosage of procaine on lung cancer cell proliferation. Eur Rev Med Pharmacol Sci 20: 4791-4795, 2016.

15 Ying B, Huang H, Li H, Song M, Wu S and Ying H: Procaine inhibits proliferation and migration and promotes cell apoptosis in osteosarcoma cells by upregulation of microRNA-133b. Oncol Res, 2017. doi: 10.3727/096504017X14878518291077. [Epub ahead of print]

16 Jiang A, Zhao H, Cai J and Jiang WG: Possible effect of musclerelaxant anaesthetics on invasion, adhesion and migration of breast cancer cells. Anticancer Res 36: 1259-1265, 2016. 
17 Zhao H, Yu H, Martin TA, Zhang Y, Chen G and Jiang WG: Effect of junctional adhesion molecule-2 expression on cell growth, invasion and migration in human colorectal cancer. Int J Oncol 48: 929-936, 2016.

18 Hooijmans CR, Geessink FJ, Ritskes-Hoitinga M and Scheffer GJ: A systematic review of the modifying effect of anaesthetic drugs on metastasis in animal models for cancer. PloS One 11: e0156152, 2016.

19 Niwa H, Rowbotham DJ, Lambert DG and Buggy DJ: Can anesthetic techniques or drugs affect cancer recurrence in patients undergoing cancer surgery? J Anesthesia 27: 731-741, 2013.

20 Kim R: Anesthetic technique and cancer recurrence in oncologic surgery: unraveling the puzzle. Cancer Metastasis Rev 36: 159177, 2016.

21 Zhang F, Wang C, Cui Y, Li S, Yao Y, Ci Y, Wang J, Hou W, Wu $\mathrm{A}$ and $\mathrm{Li} \mathrm{E}$ : Effects of propofol on several membrane characteristics of cervical cancer cell Lines. Cellular Physiol Biochem 40: 172-182, 2016.

22 Jiang Y, Gou H, Zhu J, Tian S and Yu L: Lidocaine inhibits the invasion and migration of TRPV6-expressing cancer cells by TRPV6 downregulation. Oncology Lett 12: 1164-1170, 2016.
23 Xu YJ, Li SY, Cheng Q, Chen WK, Wang SL, Ren Y and Miao $\mathrm{CH}$ : Effects of anaesthesia on proliferation, invasion and apoptosis of LoVo colon cancer cells in vitro. Anaesthesia 71: 147-154, 2016.

24 Horiuchi T, Takazawa T and Saito S: A Case of rocuroniuminduced anaphylaxis in which surgery was subsequently performed under general anesthesia without neuromuscular blocking agents. Masui 65: 299-303, 2016.

25 Aldasoro M, Jorda A, Aldasoro C, Marchio P, Guerra-Ojeda S, Gimeno-Raga M, Mauricio MD, Iradi A, Obrador E, Vila JM and Valles SL: Neuronal effects of sugammadex in combination with rocuronium or vecuronium. Int J Med Sci 14: 224-230, 2017.

26 Yue H, Han J, Liu L, Wang K and Li J: Effect of rocuronium on the bispectral index under anesthesia and tracheal intubation. Exp Ther Med 12: 3785-3789, 2016. 